\title{
Unsteady/Steady Free Convective Couette Flow of Reactive Viscous Fluid in a Vertical Channel Formed by Two Vertical Porous Plates
}

\author{
Basant K. Jha, ${ }^{1}$ Ahmad K. Samaila, ${ }^{1,2}$ and Abiodun O. Ajibade ${ }^{1}$ \\ ${ }^{1}$ Department of Mathematics, Ahmadu Bello University, Zaria, Nigeria \\ ${ }^{2}$ Department of Mathematics, Usmanu Danfodiyo University, P.M.B +234-2346, Sokoto, Nigeria
}

Correspondence should be addressed to Ahmad K. Samaila, askamba2003@yahoo.co.uk

Received 28 March 2012; Accepted 15 May 2012

Academic Editors: M. Appell, G. L. Aranovich, A. Ghoufi, and B. Merinov

Copyright (C) 2012 Basant K. Jha et al. This is an open access article distributed under the Creative Commons Attribution License, which permits unrestricted use, distribution, and reproduction in any medium, provided the original work is properly cited.

\begin{abstract}
This paper presents unsteady as well as steady-state free convection Couette flow of reactive viscous fluid in a vertical channel formed by two infinite vertical parallel porous plates. The motion of the fluid is induced due to free convection caused by the reactive nature of viscous fluid as well as the impulsive motion of one of the porous plates. The Boussinesq assumption is applied, and the nonlinear governing equations of motion and energy are developed. The time-dependent problem is solved using implicit finite difference method, and steady-state problem is solved by applying regular perturbation technique. During the course of computation, an excellent agreement was found between the well-known steady-state solutions and transient solutions at large value of time.
\end{abstract}

\section{Introduction}

The study of convection processes in porous channels is a well-developed field of investigation because of its importance to a variety of situations. For example, thermal insulations, geothermal system, surface catalysis of chemical reactions, solid matrix heat exchanger, microelectronic heat transfer equipment, porous flat collectors, coal and grain storage, petroleum industries, dispersion of chemical contaminants in various processes, nuclear waste material, and catalytic beds. Some of the examples mentioned above involve two or more fluids, multidimensional and unsteady flows [1].

The literature on the topic of unsteady as well as steadystate free convection flow problems is well surveyed by Singh et al. [2], Florio and Harnoy [3], Jha and Ajibade [4], Paul et al. [5], and Langellotto et al. [6]. Muhuri [7] presented natural convection Couette flow between two vertical porous plates when one of the plates moves with uniform acceleration. Singh [8] investigated the motion of the fluid induced by the impulsive motion of one of the plates in the presence of convection currents due to asymmetric thermal condition on the boundaries. Abdulaziz and Hashim [9] considered free convection flow between porous vertical plates with asymmetric wall temperatures and concentrations and used homotopy analysis method to solve boundary-value problems. Fang $[10,11]$ analysed unsteady velocity and temperature profiles for Couette flow and pressure-driven flow in a channel with porous walls. Unsteady flow investigations with porous boundaries include the works of Wang et al. [12], Oxarango et al. [13], and Makinde and Ogulu [14]. Makinde and Maserumule [15] presented thermal criticality and entropy analysis for a variable viscosity Couette flow.

In all previous studies the working fluid is considered as nonreactive viscous incompressible fluid. However, unsteady as well as steady-state free convection Couette flow of a reactive viscous fluid in a vertical channel formed by two vertical porous plates can be of importance for the design of equipment used in several types of engineering systems. There are many chemical reactions with important practical applications. A common configuration for such reactions is for the reactants to be made to flow over solid catalyst, with the reaction taking place on the surface of the catalyst. A full 
discussion of catalysis and description of many of its practical applications is given by Chaudhary and Merkin [16], Merkin and Chaudhary [17], and Chaudhary et al. [18]. These authors studied flow configuration and assume that the reaction takes place only on the catalytic surface and can be represented schematically by the single first-order Arrhenius kinetics. According to these authors there is a three-way coupling between fluid flow, fluid/surface temperature, and reactant species concentration. Ayeni [19] and Dainton [20] studied a realistic mathematical description of thermal explosion which include the effects of Arrhenius temperature dependence with variable preexponential factor. Recently Jha et al. [21] investigated transient natural convection flow of reactive viscous flow in a vertical channel. Most recently Hazem Attia [22] studied the effect of suction and injection on unsteady Couette flow.

The objective of the present work is to analyze the effect of suction/injection on time dependent unsteady as well as steady-state free convection Couette flow of viscous reactive fluid in a vertical channel formed by two infinite vertical parallel porous plates.

\section{Mathematical Analysis}

Consider the transient free convective Couette flow of viscous reactive fluid in a vertical channel formed by two infinite vertical parallel porous plates. The system under consideration is sketched in Figure 1. The flow is assumed transient and fully developed. The $x^{\prime}$-axis is taken along the direction of the flow and parallel to the infinite vertical porous plates and $y^{\prime}$-direction perpendicular to the flow direction. At time $t^{\prime} \leq 0$, the fluid and the porous plates are assumed to be same temperature $T_{0}$, and there is no fluid motion. At $t^{\prime}>0$, one of the porous plates $\left(y^{\prime}=H\right)$ starts moving with constant velocity and fluid generate heat due to its reactive nature causes to set up fluid motion inside the channel. In addition, at the same time the flow is subjected to suction of the fluid from one porous plate and at the same rate fluid is being injected through the other porous plate.

The fluid is assumed to be Newtonian and obeys the Boussinesq's approximation. Under the previous assumptions the energy and momentum equations in dimensional form are

$$
\begin{gathered}
\frac{\partial u^{\prime}}{\partial t^{\prime}}-v_{0} \frac{\partial u^{\prime}}{\partial y^{\prime}}=v \frac{\partial^{2} u^{\prime}}{\partial y^{\prime 2}}+g \beta\left(T^{\prime}-T_{0}\right), \\
\frac{\partial T^{\prime}}{\partial t^{\prime}}-v_{0} \frac{\partial T^{\prime}}{\partial y^{\prime}}=\alpha \frac{\partial^{2} T^{\prime}}{\partial y^{\prime 2}}+\frac{Q C_{0} A}{\rho C_{p}} \exp \left(\frac{-E}{R T^{\prime}}\right),
\end{gathered}
$$

where $T_{0}$ the initial fluid and wall temperature, $T^{\prime}$ dimensional temperature of fluid, $Q$ the heat of reaction, $A$ the rate constant, $E$ the activation energy, $R$ the universal gas constant, $C_{o}$ the initial concentration of the reactant species, $v$ kinematic viscosity, and $H$ gap between the porous plates.
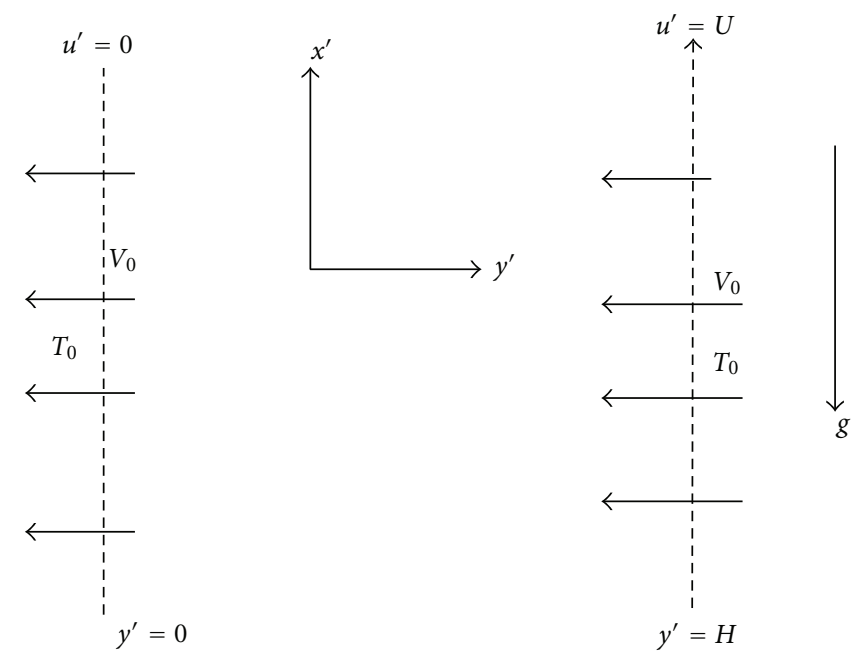

FIGURE 1: Schematic diagram of the problem.

The initial and boundary conditions to be satisfied are

$$
\begin{aligned}
& t^{\prime} \leq 0: u^{\prime}=0, \quad T^{\prime}=T_{0} \quad \text { for } 0 \leq y^{\prime} \leq h,
\end{aligned}
$$

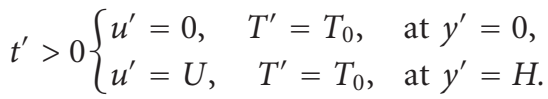

Equations (1) and (2) can be nondimensionalized using the variables

$$
\begin{gathered}
y=\frac{y^{\prime}}{H}, \quad t=\frac{t^{\prime} v}{H^{2}}, \\
u=\frac{u^{\prime}}{U}, \quad \theta=\frac{E}{R T_{0}^{2}}\left(T^{\prime}-T_{0}\right), \\
\lambda=\frac{Q C_{0} A E H^{2}}{\kappa R T_{0}^{2}} \exp \left(\frac{-E}{R T_{0}}\right), \quad \varepsilon=\frac{R T_{0}}{E}, \\
s=\frac{V_{0} H}{v}, \quad \delta=\frac{g \beta R T_{0}^{2} h^{2}}{E U v}, \quad \operatorname{Pr}=\frac{v}{\alpha} .
\end{gathered}
$$

The physical quantities used in (3) are defined in the nomenclature.

Using the expressions (3) and (1) the dimensionless momentum and energy equations are

$$
\begin{gathered}
\frac{\partial u}{\partial t}-s \frac{\partial u}{\partial y}=\frac{\partial^{2} u}{\partial y^{2}}+\delta \theta \\
\frac{\partial \theta}{\partial t}-s \frac{\partial \theta}{\partial y}=\frac{1}{\operatorname{Pr}} \frac{\partial^{2} \theta}{\partial y^{2}}+\frac{\lambda}{\operatorname{Pr}} \exp \left(\frac{\theta}{1+\varepsilon \theta}\right)
\end{gathered}
$$

while the initial and boundary conditions in dimensionless form are

$$
\begin{aligned}
& t \leq 0: u=\theta=0 \quad \text { for } 0 \leq y \leq 1 \text {, } \\
& t>0:\left\{\begin{array}{lll}
u=0, & \theta=0 & \text { at } y=0, \\
u=1, & \theta=0 & \text { at } y=1 .
\end{array}\right.
\end{aligned}
$$




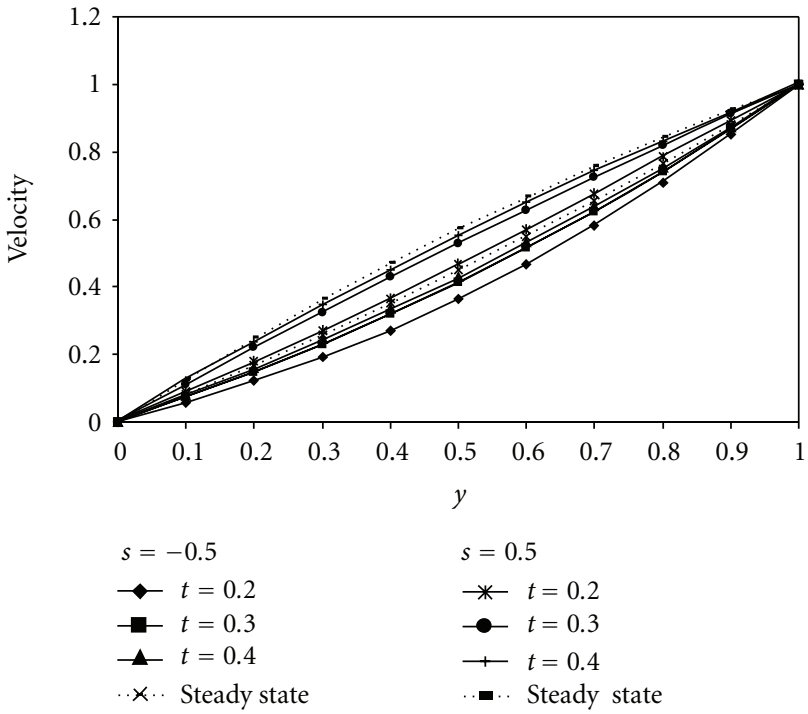

Figure 2: Velocity profile $(\varepsilon=0.01, \operatorname{Pr}=7.0, \lambda=1.0)$.

\section{Analytical Solutions}

The governing equations (4) presented in the previous section are highly nonlinear and exhibit no analytical solutions. The importance of analytical solutions which refers to steady free convection Couette flow of viscous reactive fluid relies on the chance to obtain nontrivial benchmarks to test the reliability of numerical codes developed for more complex physical situations. Analytical solutions are often an opportunity to inspect the internal consistency of mathematical models and of the approximations adopted, as well as to develop new theoretical results. The mathematical model representing the steady-state free convection Couette flow can be obtained by setting $\partial u / \partial t=0$ and $\partial \theta / \partial t=0$ in (4) to get

$$
\begin{gathered}
\frac{d^{2} u}{d y^{2}}+s \frac{d u}{d y}+\delta \theta=0, \\
\frac{d^{2} \theta}{d y^{2}}+\operatorname{Pr} s \frac{d \theta}{d y}+\lambda \exp \left(\frac{\theta}{1+\varepsilon \theta}\right)=0 .
\end{gathered}
$$

The boundary conditions are

$$
\begin{aligned}
& u=0, \quad \theta=0 \quad \text { at } y=0, \\
& u=1, \quad \theta=0 \quad \text { at } y=1 .
\end{aligned}
$$

In order to construct an approximate solution to (6) subject to (7), we employed a regular perturbation method by taking a power series expansion in the reactant consumption parameter $\lambda$ :

$$
\begin{aligned}
& \theta=\sum_{i=0}^{\infty} \theta_{i} \lambda^{i}, \\
& u=\sum_{i=0}^{\infty} u_{i} \lambda^{i} .
\end{aligned}
$$

Substituting (8) into (6) and collecting the coefficients of like powers of $\lambda$, the solution of the governing equations is obtained as

$$
\begin{gathered}
\theta=\lambda\left[\frac{1}{s \operatorname{Pr}} \frac{(1-\exp (-s \operatorname{Pr} y))}{(1-\exp (-s \operatorname{Pr}))}-\frac{y}{s \operatorname{Pr}}\right] \\
+\lambda^{2}\left\{\frac{1}{2 s \operatorname{Pr}}\left(\frac{y^{2}}{s \operatorname{Pr}}-\frac{2 y}{(s \operatorname{Pr})^{2}}+\frac{2}{(s \operatorname{Pr})^{3}}\right)\right. \\
-\frac{y}{(s \operatorname{Pr})^{2}}\left(\frac{(1+\exp (-s \operatorname{Pr} y))}{(1-\exp (-s \operatorname{Pr}))}\right) \\
+\frac{1}{(s \operatorname{Pr})^{3}} \frac{1}{(1-\exp (-s \operatorname{Pr}))}+\frac{k_{1}}{s \operatorname{Pr}} \\
\left.+k_{2} \exp (-s \operatorname{Pr} y)\right\},
\end{gathered}
$$$$
u=\frac{[1-\exp (-s y)]}{[1-\exp (s)]}
$$

$$
\begin{aligned}
+\lambda\left[\delta \left\{\frac{1}{2 s \operatorname{Pr}}\left(\frac{y^{2}}{s}-\frac{2}{s}\left\{\frac{y}{s}-\frac{1}{s^{2}}\right\}\right)\right.\right. \\
\left.+\frac{1}{z_{1}}\left\{\frac{y}{s}-\frac{1}{s^{2}}\right\}-\frac{1}{z_{1}} \frac{\exp (-s \operatorname{Pr} y)}{s^{2} \operatorname{Pr}(1-\operatorname{Pr})}\right\}
\end{aligned}
$$$$
\left.+\frac{c_{1}}{s}+c_{2} \exp (-s y)\right]
$$$$
+\lambda^{2}\left[\frac{G_{1}}{s}-\frac{\delta}{6(s \mathrm{Pr})^{2}}\left\{\frac{y^{3}}{s}-\frac{3 y^{2}}{s^{2}}+\frac{6 y}{s^{3}}-\frac{6}{s^{4}}\right\}\right.
$$$$
+\delta\left\{\frac{1}{2(s \operatorname{Pr})^{3}}+\frac{1}{2(s \operatorname{Pr})^{2}(1-\exp (-s \operatorname{Pr}))}\right\}
$$$$
\times\left\{\frac{y^{2}}{s}-\frac{2 y}{s^{2}}+\frac{2}{s^{3}}\right\}
$$$$
-\frac{\delta}{(s \operatorname{Pr})^{4}}\left(\frac{y}{s}-\frac{1}{s^{2}}\right)-\frac{\delta}{(s \operatorname{Pr})^{3}(1-\exp (-s \operatorname{Pr}))}
$$$$
\times\left\{\frac{y}{s(1-\operatorname{Pr})}-\frac{1}{s^{2}(1-\operatorname{Pr})^{2}}\right\} \exp (-s \operatorname{Pr} y)
$$$$
-\frac{\delta}{(s \operatorname{Pr})^{4}} \frac{1}{(1-\exp (-s \operatorname{Pr}))} \frac{\exp (-s \operatorname{Pr} y)}{s(1-\operatorname{Pr})}
$$$$
-\frac{\delta}{(s \operatorname{Pr})^{3}(1-\exp (-s \operatorname{Pr}))}\left\{\frac{y}{s}-\frac{1}{s^{2}}\right\}
$$$$
-\frac{k_{1}}{s \operatorname{Pr}}\left(\frac{y}{s}-\frac{1}{s^{2}}\right)+\frac{k_{2} \exp (-s \operatorname{Pr} y)}{s^{2} \operatorname{Pr}(1-\operatorname{Pr})}
$$$$
\left.+G_{2} \exp (-s y)\right]
$$ 
Steady-state skin frictions on the boundary plates is

$$
\begin{aligned}
& \tau_{0}=\left.\frac{d u}{d y}\right|_{y=0} \\
& =\frac{s}{[1-\exp (-s)]}+\lambda\left[\delta\left(\frac{\operatorname{Pr}}{z_{1} s(1-\operatorname{Pr})}-\frac{1}{s^{3} \operatorname{Pr}}\right)-c_{2} s\right] \\
& -\lambda^{2}\left[\frac{\delta}{s^{5}}\left(\frac{1}{\operatorname{Pr}^{2}}+\frac{1}{\operatorname{Pr}^{3}}+\frac{1}{\operatorname{Pr}^{4}}\right)\right. \\
& +\frac{\delta}{s^{4} \operatorname{Pr}^{2}(1-\exp (-s \operatorname{Pr}))}\left(1+\frac{1}{(1-\operatorname{Pr})^{2}}+\frac{1}{\operatorname{Pr}}\right) \\
& \left.+\frac{k_{1}}{s^{2} \operatorname{Pr}}-\frac{k_{2}}{s(1-\operatorname{Pr})}-G_{2} s\right] \\
& \tau_{1}=\left.\frac{d u}{d y}\right|_{y=1} \\
& =\frac{[s \exp (-s)]}{[1-\exp (s)]} \\
& +\lambda\left[\delta\left\{\frac{1}{2 s \operatorname{Pr}}\left(\frac{2}{s}-\frac{2}{s^{2}}\right)+\frac{s \operatorname{Pr}}{z_{1}} \frac{\exp (-s \operatorname{Pr})}{s^{2} \operatorname{Pr}(1-\operatorname{Pr})}\right\}\right. \\
& \left.-c_{2} s \exp (-s)\right] \\
& -\lambda^{2}\left[\frac{\delta}{6(s \operatorname{Pr})^{2}}\left\{\frac{3}{s}-\frac{6}{s^{2}}+\frac{6}{s^{3}}\right\}\right. \\
& +\delta\left\{\frac{1}{2(s \operatorname{Pr})^{3}}+\frac{1}{2(s \operatorname{Pr})^{2}(1-\exp (-s \operatorname{Pr}))}\right\} \\
& \times\left\{\frac{2}{s}-\frac{2}{s^{2}}\right\} \\
& -\frac{\delta}{s^{5}(\operatorname{Pr})^{4}}+\frac{\delta s \operatorname{Pr} \exp (-s \operatorname{Pr})}{(s \operatorname{Pr})^{3}(1-\exp (-s \operatorname{Pr}))} \frac{1}{s(1-\operatorname{Pr})} \\
& +\frac{\delta}{(s \operatorname{Pr})^{4}} \frac{1}{(1-\exp (-s \operatorname{Pr}))} \frac{s \operatorname{Pr} \exp (-s \operatorname{Pr})}{s(1-\operatorname{Pr})} \\
& -\frac{\delta}{s^{2}(\operatorname{Pr})^{3}(1-\exp (-s \operatorname{Pr}))} \\
& \left.-\frac{k_{1}}{s^{2} \operatorname{Pr}}-\frac{k_{2} s \operatorname{Pr} \exp (-s \operatorname{Pr})}{s^{2} \operatorname{Pr}(1-\operatorname{Pr})}-G_{2} s \exp (-s)\right] \text {. }
\end{aligned}
$$

The steady-state rate of heat transfer on the boundary plates is

$$
\begin{aligned}
N u_{0}= & \left.\frac{d \theta}{d y}\right|_{y=0} \\
= & \lambda\left[\frac{1}{(1-\exp (-s \operatorname{Pr}))}-\frac{1}{s \operatorname{Pr}}\right] \\
& -\lambda^{2}\left[\frac{1}{(s \operatorname{Pr})^{3}}+\frac{2}{(s \operatorname{Pr})^{2}(1-\exp (-s \operatorname{Pr}))}+s \operatorname{Pr} k_{2}\right],
\end{aligned}
$$

$$
\begin{aligned}
N u_{1}= & \left.\frac{d \theta}{d y}\right|_{y=1} \\
=\lambda & {\left[\frac{\exp (-s \operatorname{Pr})}{(1-\exp (-s \operatorname{Pr}))}-\frac{1}{s \operatorname{Pr}}\right] } \\
& +\lambda^{2}\left[\frac{1}{(s \operatorname{Pr})^{3}}(s \operatorname{Pr}-1)-\frac{1}{(s \operatorname{Pr})^{2}(1-\exp (-s \operatorname{Pr}))}\right. \\
& \quad \times\{1+(1-s \operatorname{Pr}) \exp (-s \operatorname{Pr})\} \\
& \left.\quad-s \operatorname{Pr}_{2} \exp (-s \operatorname{Pr})\right]
\end{aligned}
$$

The constants $c_{1}, c_{2}, k_{1}, k_{2}, A, B, A_{1}, B_{1}, G_{1}, G_{2}$ are defined in the appendix section.

\section{Numerical Solutions}

To solve the time-dependent equation (4), the differential equations have been transformed into the corresponding finite difference equation. The procedure involves discretization of the momentum and energy equations into the finite difference equations at the grid point $(i, j)$ in which the time derivatives are approximated by the backward difference while the spatial derivatives are replaced by the central difference formula. The above equations are solved by Thomas algorithm by manipulating into a system of linear algebraic equations in the tridiagonal form.

In each time step, firstly the temperature field has been solved and then the velocity field is evaluated using the already known values of the temperature field. The process of computation is advanced until a solution is approached by satisfying the following convergence criterion:

$$
\frac{\sum\left|A_{i, j+1}-A_{i, j}\right|}{M|A|_{\max }}<10^{-5}
$$

with respect to temperature and velocity fields. Here $A_{i, j}$ stands for the velocity or temperature fields, $M$ is the number of interior grid points, and $|A|_{\max }$ is the maximum absolute value of $A_{i, j}$.

\section{Results and Discussion}

The basic parameters that governed this flow are the reactant consumption parameter $(\lambda)$, the activation energy parameter $(\varepsilon)$, the Grashof number $(\delta)$, the Prandtl number (Pr) which is inversely proportional to the thermal diffusivity of the working fluid, and suction/injection parameter $(s)$, which were simultaneously applied each to opposite porous plates of the channel at the same rate. For the purpose of discussion, some numerical calculations are carried out for dimensionless velocity $(u)$, temperature $(\theta)$, skin friction $(\tau)$, and the rate of heat transfer $(N u)$. In the entire computation the value of Grashof number $(\delta)$ is taken to be unity. The effect of various parameter on the flow are presented in 


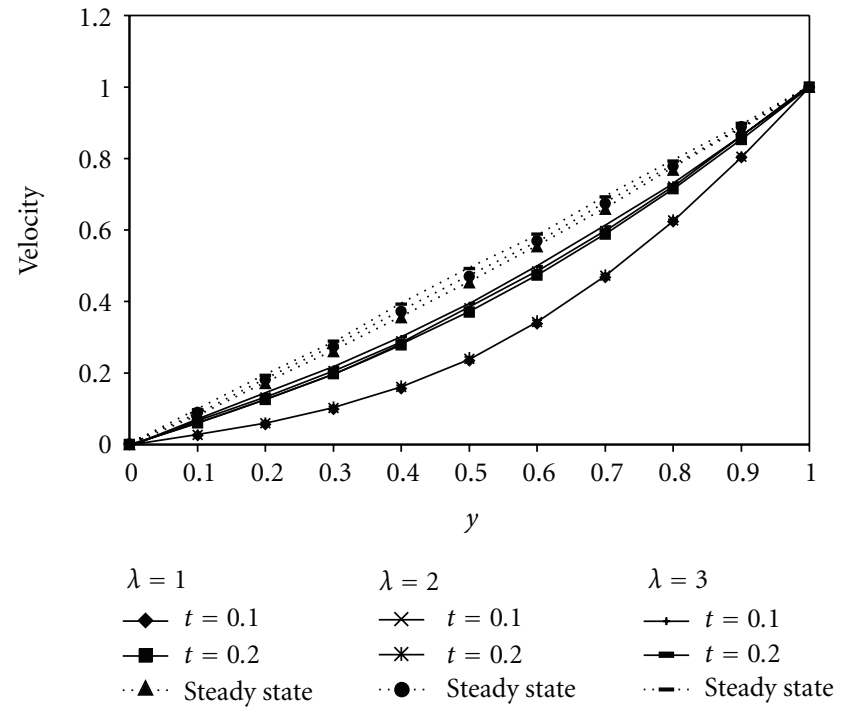

Figure 3: Velocity profile $(\varepsilon=0.01, \operatorname{Pr}=7.0, s=0.5)$.

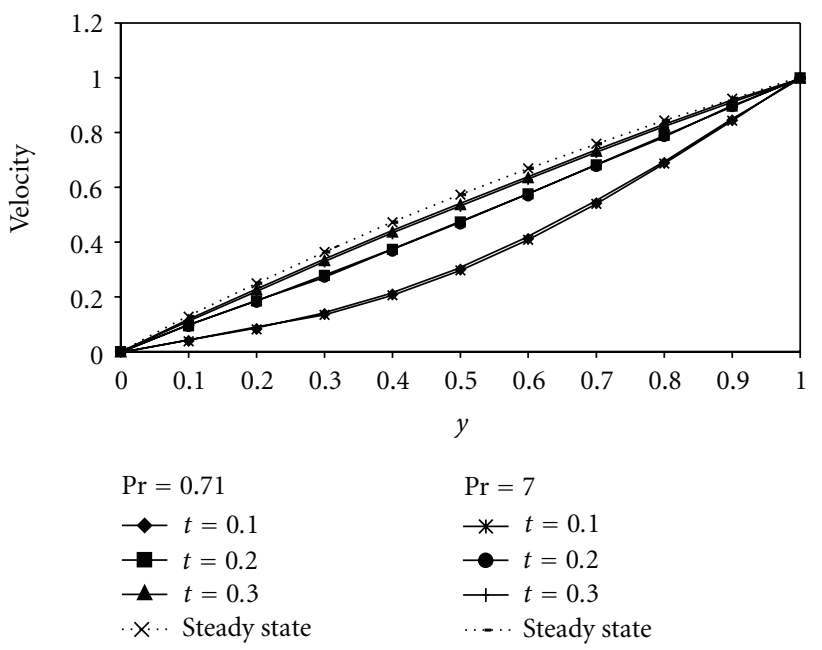

FIGURE 4: Velocity profile $(\varepsilon=0.01, s=0.5, \lambda=1.0)$.

graphical form in Figures 2 to 17 so as to clearly reveal the influence of each governing parameter on the flow. Figure 2 describes the influence of $s$ and $t$ on the velocity profile within the channel. This figure reveals that as time increases, the velocity increases. This is the consequence of temperature increase with time. This figure also reflects that when suction takes place on the porous plate at $y=0(s>0)$ fluid velocity is higher compared to a situation when injection takes place on the porous plate at $y=0(s<0)$. This is physically true since suction on the porous plate $y=0$ happens concurrently with injection on the moving porous plate $(y=1)$ which acts in support of the motion of the porous plate $(y=1)$, and hence an increase in fluid velocity is the consequence. On the other hand $(s<0)$ means injection on the plate $y=0$ which translates to a corresponding suction on the plate $(y=1)$ and this act against the influence of the impulsive motion of the porous plate. The effect of reactant consumption parameter and time on velocity

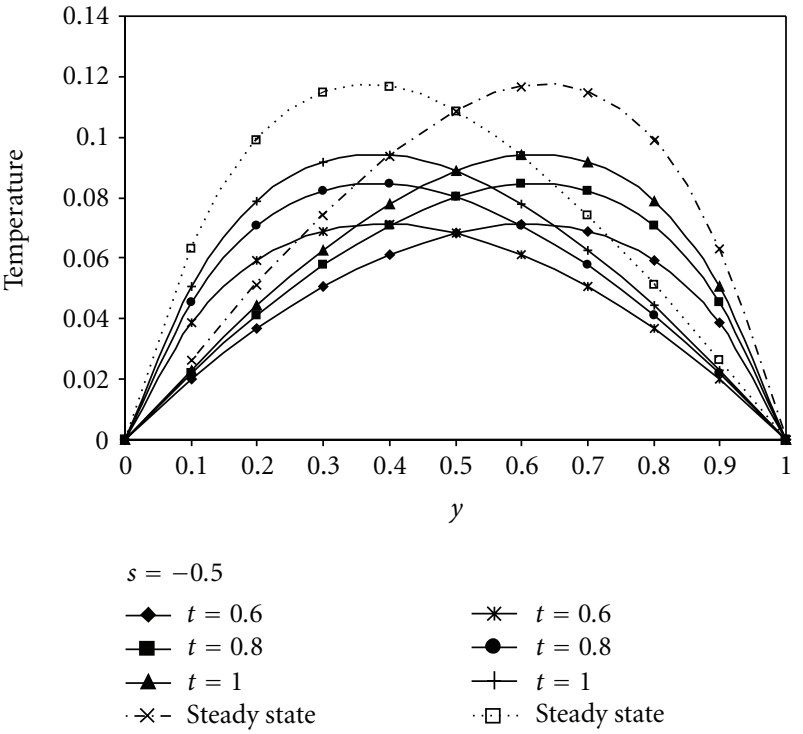

Figure 5: Temperature profile $(\varepsilon=0.01, \operatorname{Pr}=7.0, \lambda=1.0)$.

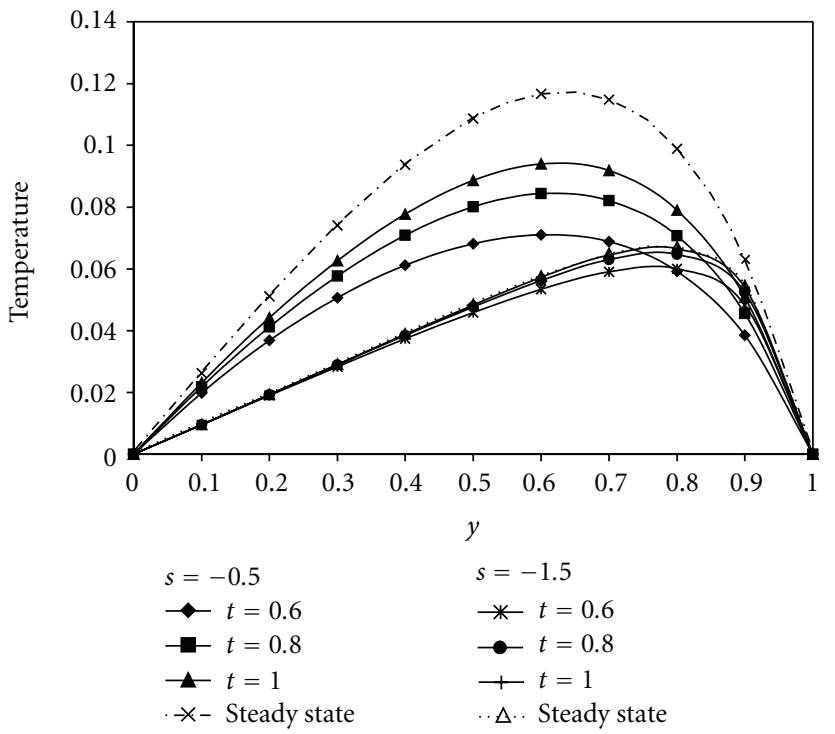

Figure 6: Temperature profile $(\varepsilon=0.01, \operatorname{Pr}=7.0, \lambda=1.0)$.

profile is depicted in Figure 3. This figure shows that as $\lambda$ increases the velocity increases. This physical fact can be explained, as reaction increases in the fluid, the temperature increases which causes velocity increase. This figure also reflects that the time required reaching steady-state velocity increases as $\lambda$ increases. From the figure it is observed that the influence of $\lambda$ on velocity is almost negligible when the time is small. However, at steady state, the velocity is observed to increase as reactant consumption parameter increases. Figure 4 reflects unsteady as well as steady-state velocity profiles for different value of nondimensional time and Prandtl number. It is evident from the figure that as time increases the velocity increases. Figure 4 also shows that the Prandtl number has insignificant effect on unsteady and steady-state velocity. Figure 5 shows the influence of 


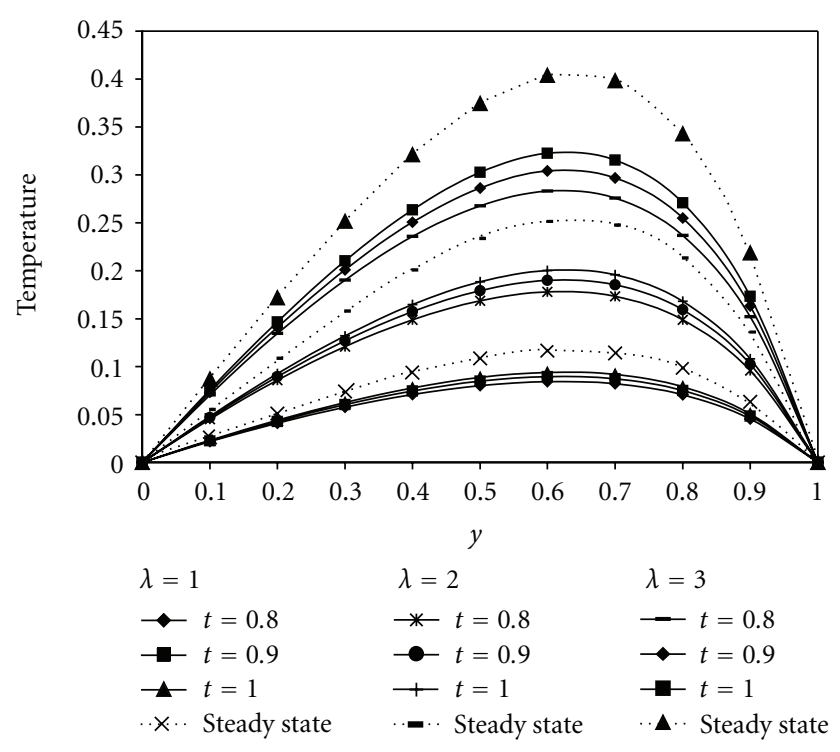

FIgURE 7: Temperature profile for $(\varepsilon=0.01, s=0.5$, Pr $=7.0)$.

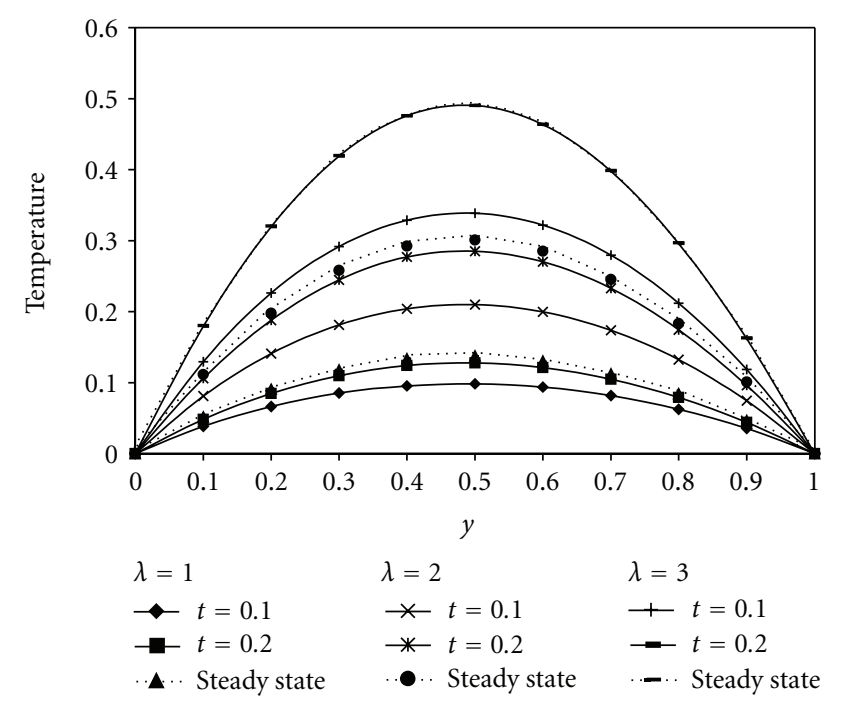

Figure 8: Temperature profile $(\varepsilon=0.01, \operatorname{Pr}=0.71, s=0.5)$.

$s$ on the temperature profiles of water $(\mathrm{Pr}=7.0)$ within the channel. It is seen from the figure that temperature increases with time. In addition, in case of suction at $y=0$, velocity is maximum near the left plate $(y=0)$, and in case of injection the maximum is shifted towards the right porous plate $(y=1)$, and hence we conclude that there is no symmetry in the temperature profile in the presence of suction/injection. Figure 6 describes the behaviour of unsteady as well as steady-state temperature profiles as a function of time for different value of $s(s=-0.5,-1.5)$. In this figure, temperature is observed to be high near the plate with injection $(y=1)$. Figure 7 reveals the influence of $\lambda$ on the temperature profile. It is reflected from this figure that as time increases the temperature increases. It is evident from Figure 7 that the time required to reach steady state temperature increases as reactant consumption parameter

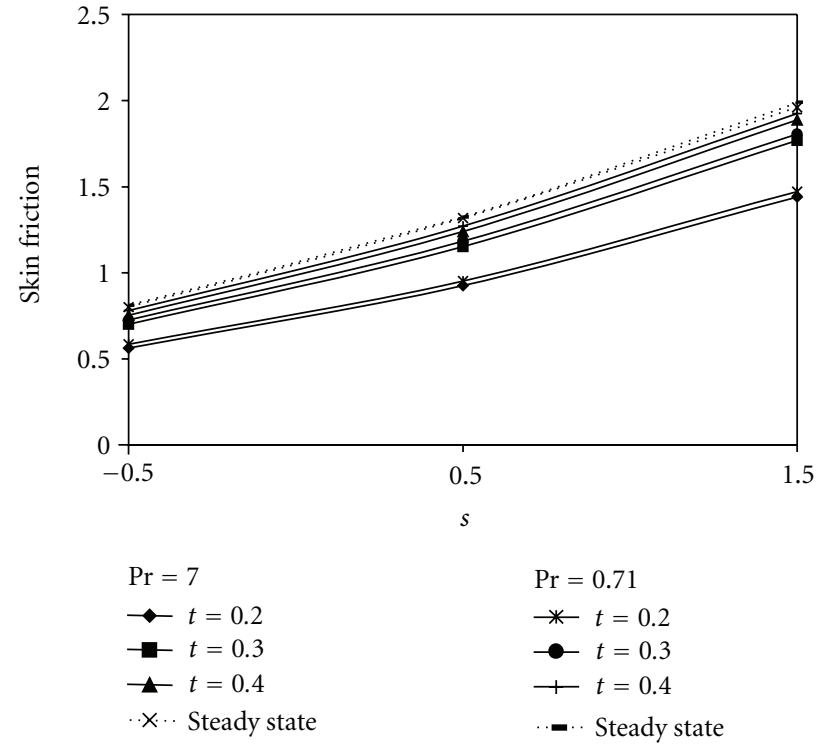

Figure 9: Variation of skin friction $(\varepsilon=0.01, \lambda=1.0)$ at $y=0$.

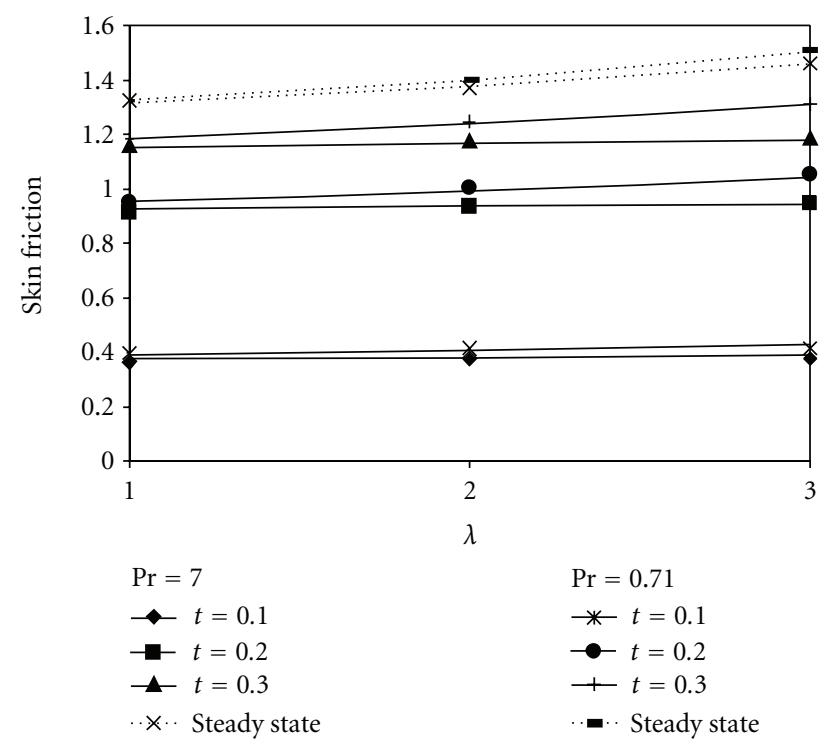

FIGURE 10: Variation of skin friction $(\varepsilon=0.01, s=0.5, \lambda=1.0)$ at $y=0$.

increases. Variation of temperature as a function of reactant consumption parameter and time is illustrated in Figure 8. It is clear from the figure that as $\lambda$ increases the temperature increases. It is also evident that the time required to reach steady state is strongly dependent on $\lambda$ (i.e., time required to reach steady state is high for high value of $\lambda$ ). Variation of skin friction for water $(\operatorname{Pr}=7.0)$ and air $(\operatorname{Pr}=0.71)$ at the plate $y=0$ and $y=1$ is shown in Figures 9, 10, and 11 . These figures reflect that as time increases the skin friction increases and finally attains its steady-state value. The effect of suction/injection parameter and the nondimensional time on the skin friction is shown in Figure 9. It is clear from the figure that the skin friction is directly proportional to nondimensional time and suction/injection parameter 


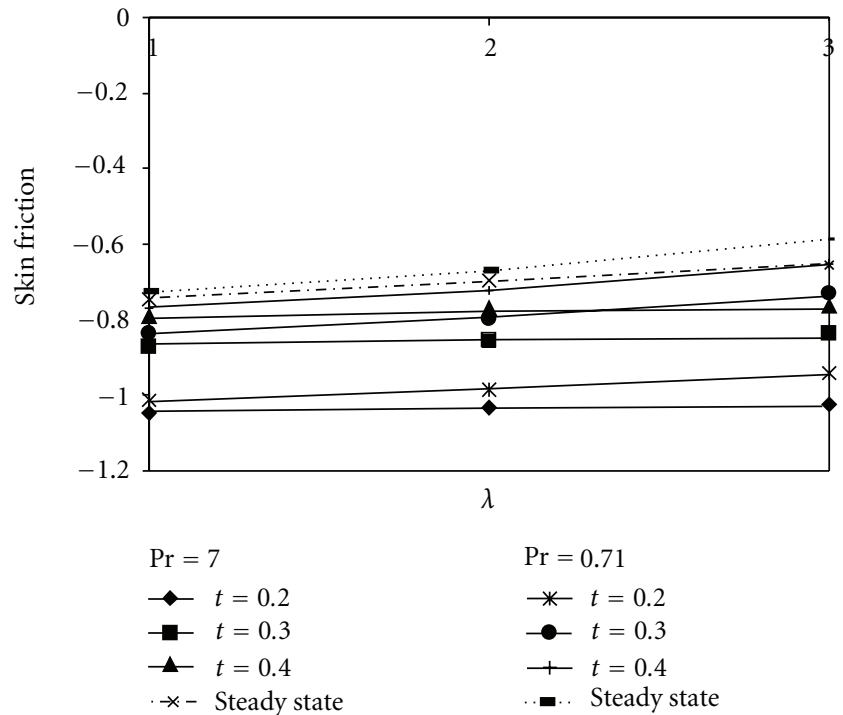

FIGURE 11: Variation of skin friction $(\varepsilon=0.01, s=0.5)$ at $y=1$.

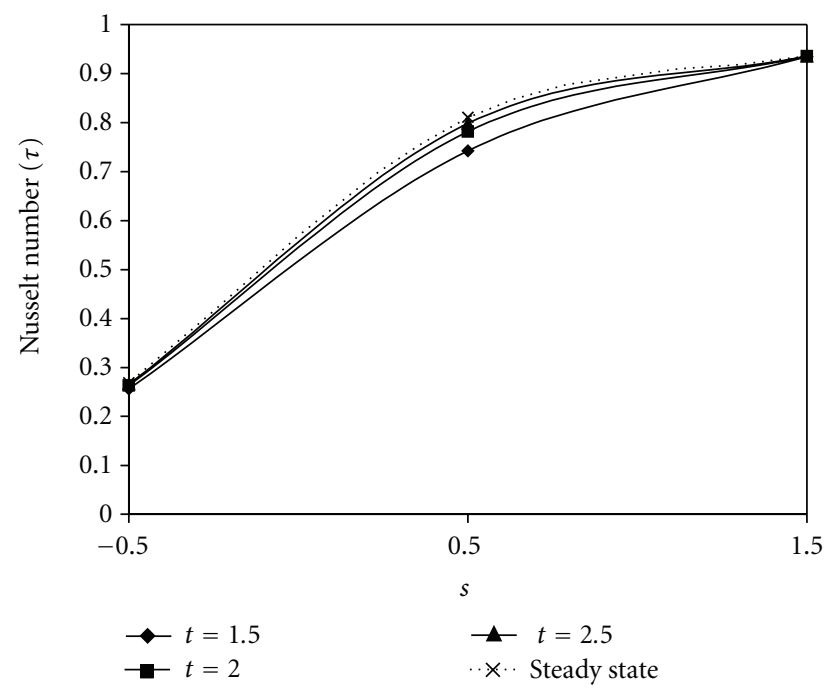

Figure 12: Variation of Nusselt number $(\varepsilon=0.01, \lambda=1.0, \operatorname{Pr}=$ 7.0) at $y=0$.

until steady-state value is attained. This figure also reveals monotonic increase in the skin friction as sincreases. This is due to the fact that as $s$ increases the velocity increases and consequently there is higher skin friction at the boundary. Figures 10, and 11 show the influence of time and reactant consumption parameter on the skin-friction at $y=0$ and $y=1$. From the two figures it is clear that the skin-friction increases as time increases until steady-state value is attained. Figures 9, 10, and 11 also reflect that the skin friction is always higher in the case of air $(\mathrm{Pr}=0.71)$ than water $(\mathrm{Pr}=$ 7.0). The rate of heat transfer which is expressed as Nusselt number $(N u)$ at $y=0$ and $y=1$ is shown in Figures 12, 13, 14, 15, 16, and 17. Figures 12 and 13 show the influence of $s$ on the rate of heat transfer. Figure 12 reveals that the rate of heat transfer increases as nondimensional time and

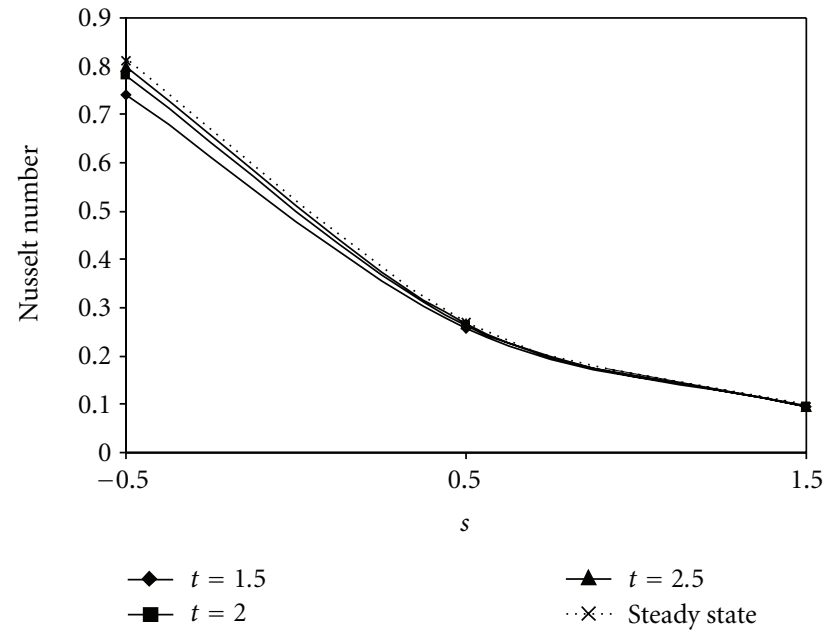

FIGURE 13: Variation of Nusselt number $(\varepsilon=0.01, \lambda=1.0, \operatorname{Pr}=$ 7.0) at $y=1$.

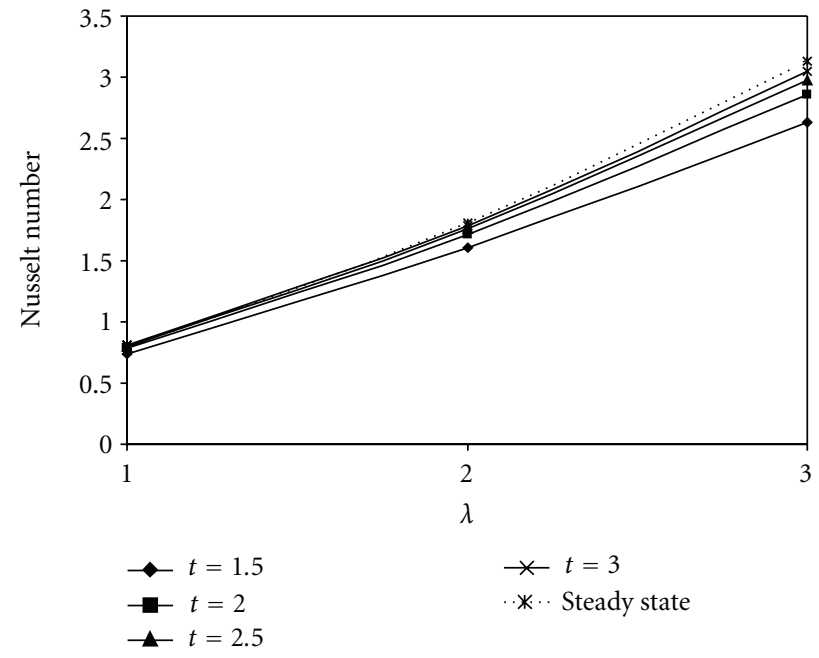

FIGURE 14: Variation of Nusselt number $(s=0.5, \varepsilon=0.01, \operatorname{Pr}=$ 7.0) at $y=0$.

suction/injection parameter increases until a steady-state value is attained. Figure 13 shows monotonic decrease in rate of heat transfer as $s$ increases. It is reflected from this figure that both the transient and steady-state rate of heat transfer coincide at large values of $s$ and $t$. Figures 14 and 15 show the variation of reactant consumption parameter on the rate of heat transfer. These two figures reveal that there is a monotonic increase in the rate of heat transfer at $(y=0, y=1)$ corresponding to water $(\operatorname{Pr}=7.0)$ and air $(\mathrm{Pr}=0.71)$. This is due to the higher temperature gradient between fluid and porous plates. It is also observed from the figure that as time increases the rate of heat transfer increases until steady-state Nusselt number is reached. Figures 16 and 17 show the influence of reactant consumption parameter with time on the Nusselt number. It is reflected from these figures that the rate of heat transfer is directly proportional to 


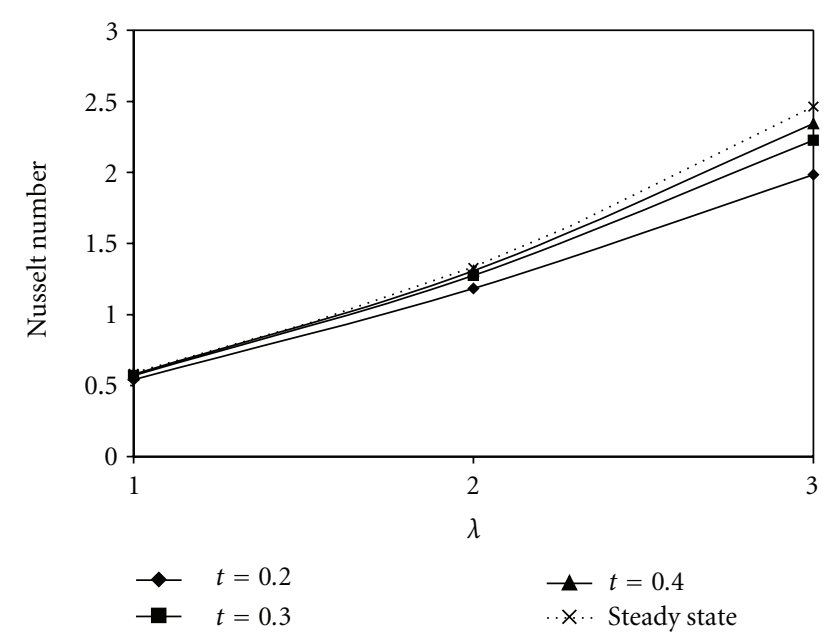

Figure 15: Variation of Nusselt number $(s=0.5, \varepsilon=0.01, \operatorname{Pr}=$ $0.71)$ at $y=0$.

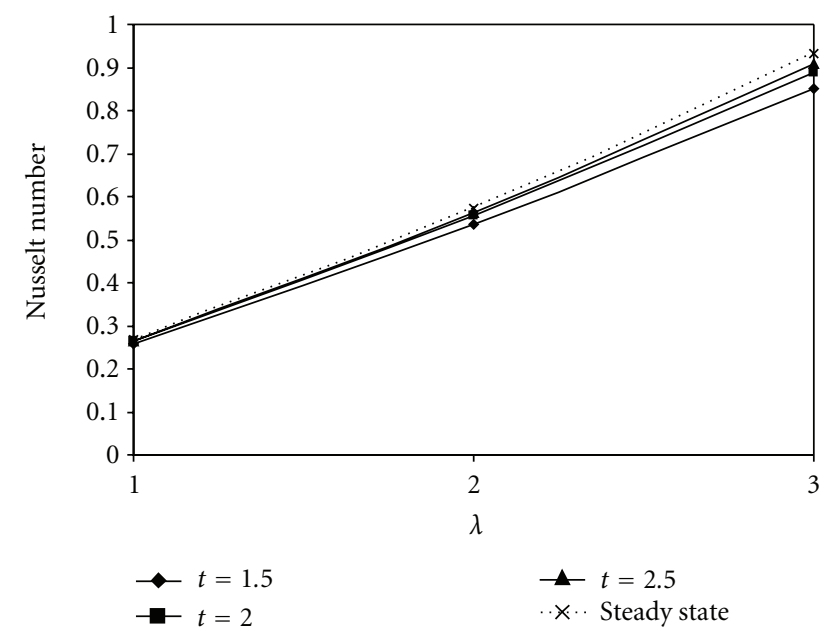

FIGURe 16: Variation of Nusselt number $(s=0.5, \varepsilon=0.01, \operatorname{Pr}=$ 7.0) at $y=1$.

the reactant consumption parameter. These two figures also show that as time increase the rate of heat transfer increases until steady-state value is reached.

\section{Conclusion}

The problem of unsteady as well as steady-state natural convection Couette flow of reactive viscous fluid in a vertical channel formed by two vertical porous plates has been presented. The velocity field and temperature field are obtained analytically by perturbation series method for steady free convective Couette flow of viscous reactive fluid in a vertical channel formed by two vertical porous plates and numerically by implicit finite difference technique for unsteady free convective Couette flow of viscous reactive fluid in a vertical channel formed by two vertical porous plates. Graphical results for the velocity, temperature, skin

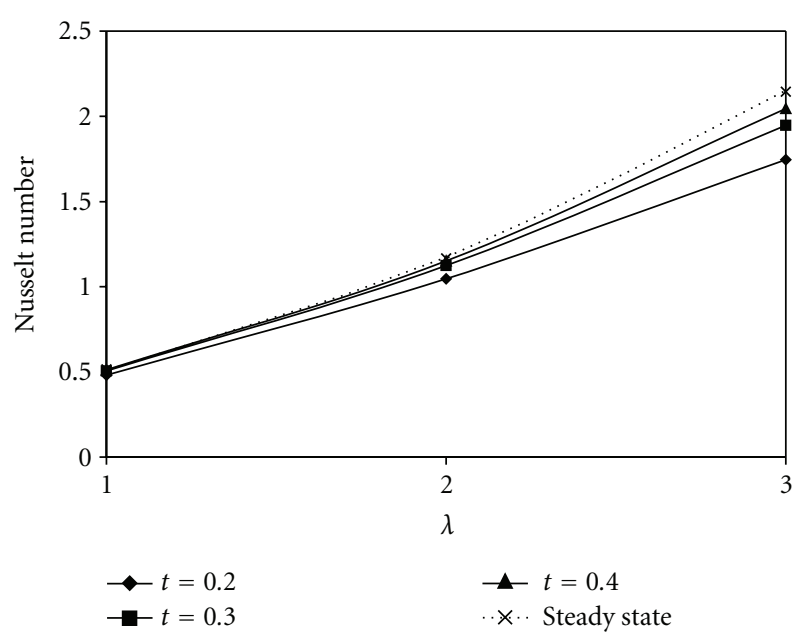

FIGURE 17: Variation of Nusselt number $(s=0.5, \varepsilon=0.01$, $\mathrm{Pr}=$ $0.71)$ at $y=1$.

friction, and the Nusselt number variations were presented and discussed for various physical parametric values.

The main findings are as follows.

(i) Skin friction is always higher in the case of air $(\mathrm{Pr}=$ $0.71)$ than water $(\operatorname{Pr}=7.0)$.

(ii) It is also seen that increase in $\lambda$ increases heat transfer on the porous plates.

(iii) The heat transfer is higher at left porous plate $y=$ 0 where injection takes place in comparison to right plate where suction takes place $y=1$.

(iv) The introduction of suction/injection has distorted the symmetric nature of the flow.

(v) During the course of computation it is observed that at steady state the effect of Pr on the fluid flow is to increase the velocity and temperature as Pr increases when injection is considered $(s<0)$ at $y=0$ while fluid velocity and temperature decreases as $\mathrm{Pr}$ increases in the presence of suction $(s>0)$ at $y=0$, which is not true in transient case (i.e., velocity and temperature decreases as Pr increases).

\section{Appendix}

Consider

$$
\begin{aligned}
c_{1}= & \frac{\delta}{[1-\exp (-s)]}\left\{\frac{1}{z_{1}}+\frac{1}{s^{2} \operatorname{Pr}}-\frac{1}{2 s \operatorname{Pr}}-\frac{1}{s^{2} \operatorname{Pr}^{2}(1-\operatorname{Pr})}\right\} \\
& -\delta\left\{\frac{1}{s^{3} \operatorname{Pr}}+\frac{1}{z_{1} s}-\frac{1}{z_{1} s \operatorname{Pr}(1-\operatorname{Pr})}\right\},
\end{aligned}
$$




$$
\begin{aligned}
& c_{2}=\frac{\delta}{[1-\exp (-s)]}\left\{\frac{1}{2 s^{2} \operatorname{Pr}}+\frac{1}{s^{3} \operatorname{Pr}^{2}(1-\operatorname{Pr})}\right\} \\
& -\frac{\delta}{s[1-\exp (-s)]}\left\{\frac{1}{z_{1}}+\frac{1}{s^{2} \operatorname{Pr}}\right\}, \\
& k_{1}=-\frac{1}{2}\left\{\frac{1}{s \operatorname{Pr}}-\frac{2}{(s \operatorname{Pr})^{2}}+\frac{2}{(s \operatorname{Pr})^{3}}\right\} \frac{1}{[1-\exp (-s \operatorname{Pr})]} \\
& +\frac{1}{s \operatorname{Pr}} \frac{[1+\exp (-s \operatorname{Pr})]}{[1-\exp (-s \operatorname{Pr})]^{2}}-\frac{1}{(s \operatorname{Pr})^{2}} \frac{1}{[1-\exp (-s \operatorname{Pr})]^{2}} \\
& +\frac{\exp (-s \operatorname{Pr})}{(s \operatorname{Pr})^{2}[1-\exp (-s \operatorname{Pr})]^{2}}+\frac{1}{(s \operatorname{Pr})^{3}} \frac{\exp (-s \operatorname{Pr})}{[1-\exp (-s \operatorname{Pr})]}, \\
& k_{2}=-\frac{k_{1}}{s \operatorname{Pr}}-\frac{1}{(s \operatorname{Pr})^{3}[1-\exp (-s \operatorname{Pr})]}-\frac{1}{(s \operatorname{Pr})^{4}}, \\
& A=\frac{1}{s^{6} \operatorname{Pr}^{2}}+\frac{1}{s^{6} \operatorname{Pr}^{3}}+\frac{1}{s^{6} \operatorname{Pr}^{4}} \frac{k_{1}}{s^{3} \operatorname{Pr}}+\frac{k_{2}}{s^{2} \operatorname{Pr}(1-\operatorname{Pr})}, \\
& B=\frac{1}{[1-\exp (-s \operatorname{Pr})]} \\
& \times\left\{\frac{1}{(1-\operatorname{Pr})^{2} s^{5} \operatorname{Pr}^{3}}+\frac{1}{s^{5} \operatorname{Pr}^{2}}-\frac{1}{s^{5} \operatorname{Pr}^{4}(1-\operatorname{Pr})}+\frac{1}{s^{5} \operatorname{Pr}^{3}}\right\}, \\
& A_{1}=\frac{1}{6(s \operatorname{Pr})^{2}}\left\{\frac{1}{s}-\frac{3}{s^{2}}+\frac{6}{s^{3}}-\frac{6}{s^{4}}\right\} \\
& -\left\{\frac{1}{2(s \operatorname{Pr})^{3}}+\frac{1}{2(s \operatorname{Pr})^{2}[1-\exp (-s \operatorname{Pr})]}\right\} \\
& \times\left\{\frac{1}{s}-\frac{2}{s^{2}}+\frac{2}{s^{3}}\right\} \text {, } \\
& B_{1}=\frac{1}{(s \operatorname{Pr})^{4}}\left\{\frac{1}{s}-\frac{1}{s^{2}}\right\}+\frac{1}{(s \operatorname{Pr})^{3}} \frac{1}{[1-\exp (-s \operatorname{Pr})]} \\
& \times\left\{\frac{1}{s(1-\operatorname{Pr})}-\frac{1}{s^{2}(1-\operatorname{Pr})^{2}}\right\} \exp (-s \operatorname{Pr}) \\
& +\frac{1}{(s \operatorname{Pr})^{4}} \frac{1}{[1-\exp (-s \operatorname{Pr})]} \frac{\exp (-s \operatorname{Pr})}{s(1-\operatorname{Pr})} \\
& +\frac{1}{(s \operatorname{Pr})^{3}}\left\{\frac{1}{s}-\frac{1}{s^{2}}\right\} \frac{1}{[1-\exp (-s \operatorname{Pr})]} \\
& +\frac{k}{s \operatorname{Pr}}\left\{\frac{1}{s}-\frac{1}{s^{2}}\right\}-\frac{k_{2} \exp (-s \operatorname{Pr})}{s^{2} \operatorname{Pr}(1-\operatorname{Pr})}, \\
& G_{1}=-\delta[A+B] s-s G_{2}, \\
& G_{2}=\delta \frac{\left[(A+B)+\left(A_{1}+B_{1}\right)\right]}{[\exp (-s)-1]} .
\end{aligned}
$$

\section{Nomenclature}

$C_{p}$ : Specific heat of the fluid at constant pressure

$E$ : Activation energy

$g$ : Acceleration due to gravity
$H$ : Gap between the channels

$N u_{0}$ : Nusselt number at $y=0$

$N u_{1}$ : Nusselt number at $y=1$

Pr: Prandtl number

Q: Heat reaction parameter

$R: \quad$ Universal gas constant

$s: \quad$ Suction/injection parameter

$t^{\prime}$ : Dimensional time

$t$ : Dimensionless time

$T^{\prime}:$ Dimensional temperature of the fluid

$T_{0}$ : Initial temperature of the fluid

$u^{\prime}$ : Dimensional velocity of the fluid

$u$ : Dimensionless velocity of the fluid

$x^{\prime}$ : Dimensional coordinate parallel to channel

$y^{\prime}$ : Dimensional coordinate perpendicular to channel

$y: \quad$ Dimensionless coordinate.

\section{Greek Letters}

$\beta$ : Volumetric coefficient of thermal expansion

$\rho$ : Density of the fluid

$\tau_{0}$ : Dimensionless skinfriction at $y=0$

$\tau_{1}$ : Dimensionless skin friction at $y=1$

$\alpha$ : Thermal diffusivity

$\theta$ : Dimensionless temperature

$\lambda$ : Reactant consumption parameter

$v$ : Kinematic viscosity

$\varepsilon:$ Activation energy parameter

$\delta$ : Grashof number.

\section{Acknowledgment}

The author A. K. Samaila is thankful to Usmanu Danfodiyo University, Sokoto, for financial support.

\section{References}

[1] S. Mahmud and R. Andrew Fraser, "Flow, thermal, and entropy generation characteristics inside a porous channel with viscous dissipation," International Journal of Thermal Sciences, vol. 44, no. 1, pp. 21-32, 2005.

[2] A. K. Singh, H. R. Gholami, and V. M. Soundalgekar, "Transient free convection flow between two vertical parallel plates," Heat and Mass Transfer/Waerme- und Stoffuebertragung, vol. 31, no. 5, pp. 329-331, 1996.

[3] L. A. Florio and A. Harnoy, "Augmenting natural convection in a vertical flow path through transverse vibrations of an adiabatic wall," Numerical Heat Transfer A, vol. 52, no. 6, pp. 497-530, 2007.

[4] B. K. Jha and A. O. Ajibade, "Free convective flow between vertical porous plates with periodic heat input," ZAMM Zeitschrift fur Angewandte Mathematik und Mechanik, vol. 90, no. 3, pp. 185-193, 2010.

[5] T. Paul, B. K. Jha, and A. K. Singh, "Transient natural convection in a vertical channel," International Journal of Applied Mechanics and Engineering, vol. 6, no. 4, pp. 913-922, 2001.

[6] L. Langellotto, O. Manca, and S. Nardini, "Numerical investigation of transient natural convection in air in a convergent vertical channel symmetrically heated at uniform heat flux," Numerical Heat Transfer A, vol. 51, no. 11, pp. 1065-1086, 2007. 
[7] P. K. Muhuri, "Flow formation in Couette motion in magnetohydrodynamics with suction," Journal of the Physical Society of Japan, vol. 18, no. 11, pp. 1671-1675, 1963.

[8] A. K. Singh, "Natural convection in unsteady Couette motion," Defence Science Journal, vol. 38, no. 1, pp. 35-41, 1988.

[9] O. Abdulaziz and I. Hashim, "Fully developed free convection heat and mass transfer of a micropolar fluid between porous vertical plates," Numerical Heat Transfer A, vol. 55, no. 3, pp. 270-288, 2009.

[10] T. Fang, "Further discussion on the incompressible pressuredriven flow in a channel with porous walls," International Communications in Heat and Mass Transfer, vol. 31, no. 4, pp. 487-500, 2004.

[11] T. Fang, "A note on the incompressible couette flow with porous walls," International Communications in Heat and Mass Transfer, vol. 31, no. 1, pp. 31-41, 2004.

[12] J. Wang, Z. Gao, G. Gan, and D. Wu, "Analytical solution of flow coefficients for a uniformly distributed porous channel," Chemical Engineering Journal, vol. 84, no. 1, pp. 1-6, 2001.

[13] L. Oxarango, P. Schmitz, and M. Quintard, "Laminar flow in channels with wall suction or injection: a new model to study multi-channel filtration systems," Chemical Engineering Science, vol. 59, no. 5, pp. 1039-1051, 2004.

[14] O. D. Makinde and A. Ogulu, "The effect of thermal radiation on the heat and mass transfer flow of a variable viscosity fluid past a vertical porous plate permeated by a transverse magnetic field," Chemical Engineering Communications, vol. 195, no. 12, pp. 1575-1584, 2008.

[15] O. D. Makinde and R. L. Maserumule, "Thermal criticality and entropy analysis for a variable viscosity Couette flow," Physica Scripta, vol. 78, no. 1, Article ID 015402, 2008.

[16] M. A. Chaudhary and J. H. Merkin, "Free-convection stagnation-point boundary layers driven by catalytic surface reactions: I the steady states," Journal of Engineering Mathematics, vol. 28, no. 2, pp. 145-171, 1994.

[17] J. H. Merkin and M. A. Chaudhary, "Free-convection boundary layers on vertical surfaces driven by an exothermic surface reaction," Quarterly Journal of Mechanics and Applied Mathematics, vol. 47, no. 3, pp. 405-428, 1994.

[18] M. A. Chaudhary, A. Liñan, and J. H. Merkin, "Free convection boundary layers driven by exothermic surface reactions: critical ambient temperatures," Mathematical Engineering in Industry, vol. 5, no. 2, pp. 129-145, 1996.

[19] R. O. Ayeni, "On the explosion of chain-thermal reaction," Journal of the Australian Mathematical Society, vol. 24, pp. 194-202, 1982.

[20] F. S. Dainton, Chain Reaction, An Introduction Wiley, New York, NY, USA, 1960.

[21] B. K. Jha, A. K. Samaila, and A. O. Ajibade, "Transient freeconvective flow of reactive viscous fluid in a vertical channel," International Communications in Heat and Mass Transfer, vol. 38, no. 5, pp. 633-637, 2011.

[22] A. Hazem Attia, "The effect of suction and injection on unsteady Couette flow," Kragujevac Journal of Science, vol. 32, pp. 17-24, 2010. 

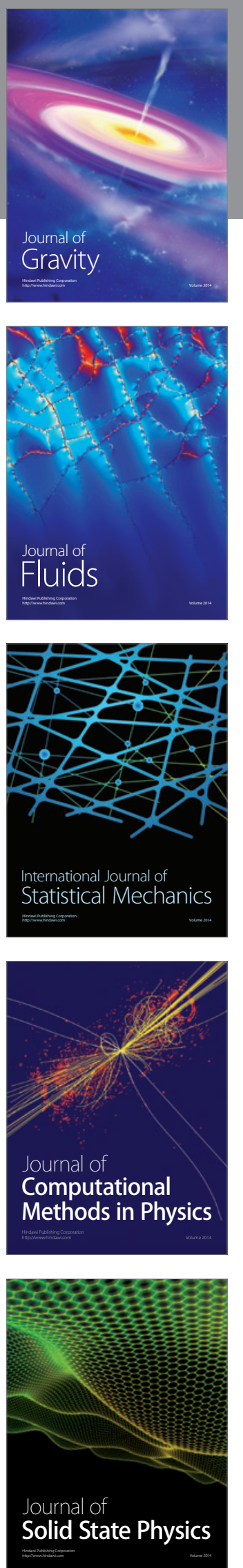
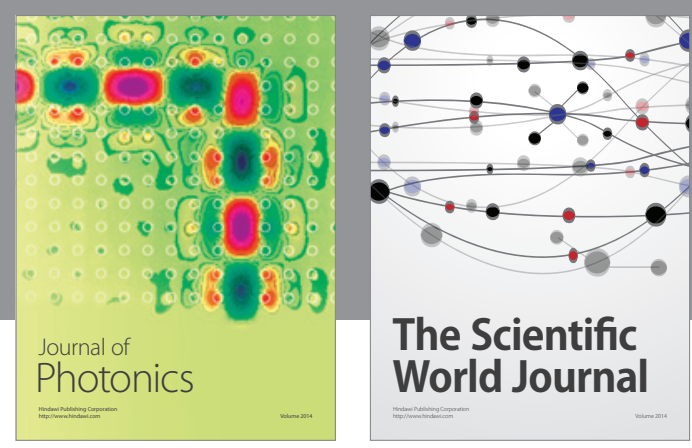

The Scientific World Journal

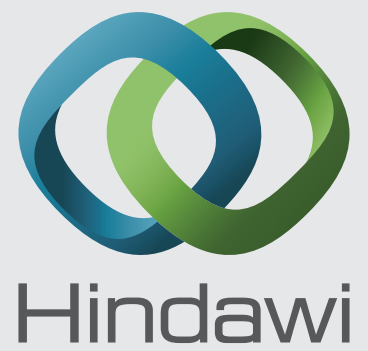

Submit your manuscripts at http://www.hindawi.com
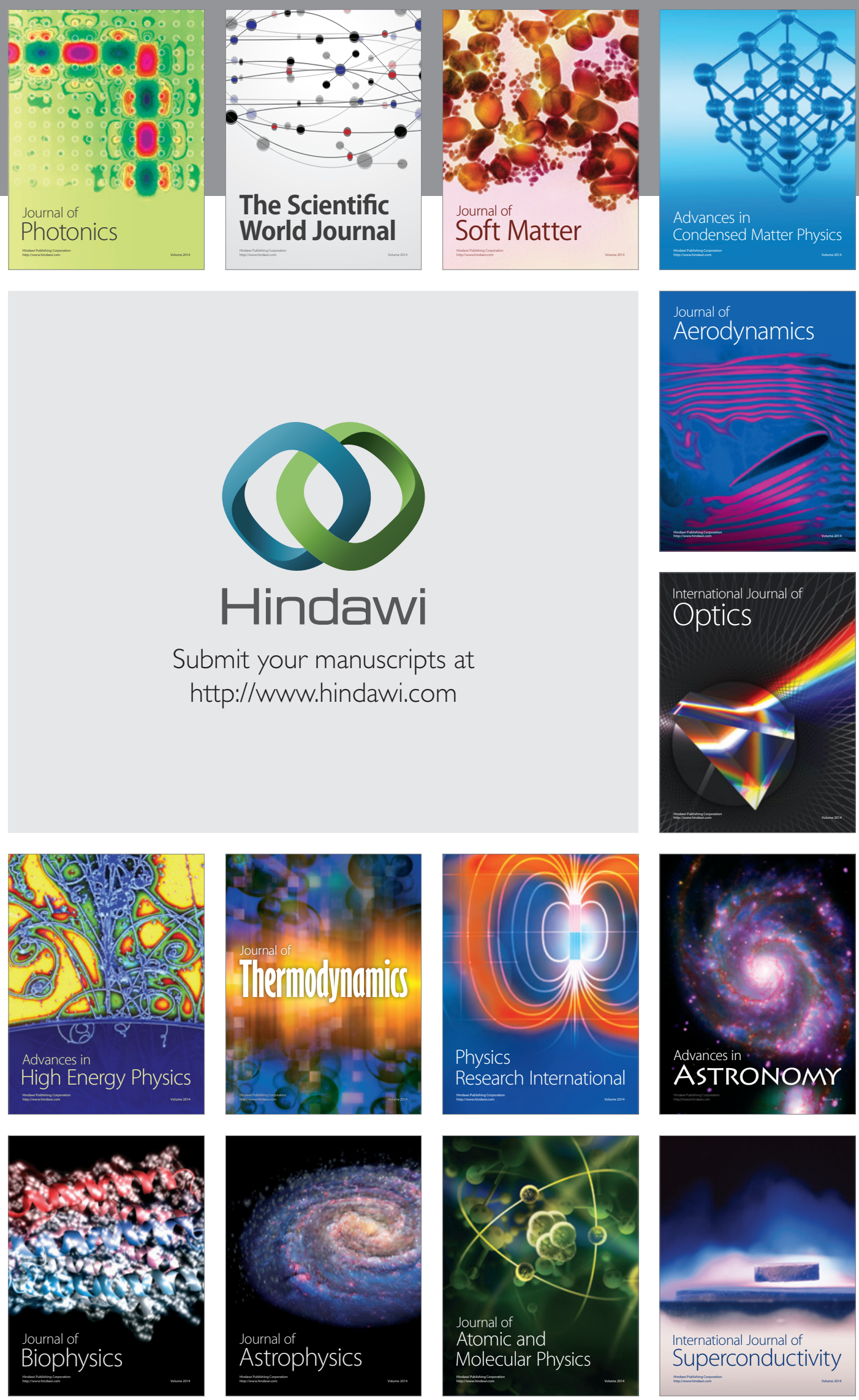
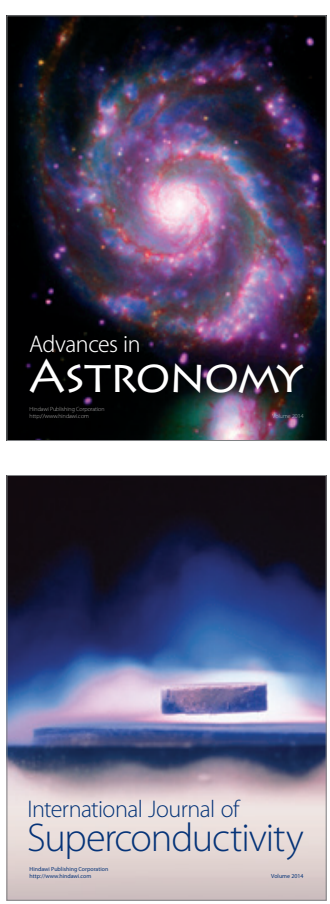